\title{
NILAI KARAKTER KREATIF DAN BERSAHABAT/KOMUNIKTIF DALAM UNGKAPAN BIJAK DI AKUN TWITTER @KATA2BIJAK
}

\author{
Mia Nur Insani' ${ }^{1}$, Agus Budi Wahyudi \\ ${ }^{1,2}$ Fakultas Keguruan dan Ilmu Pendidikan, Universitas Muhammadiyah Surakarta \\ la310170176@student.ums.ac.id, 2abw186@ums.ac.id
}

\begin{abstract}
Abstrak
Bahasa yang dikategorikan sebagai ungkapan-ungkapan tidak bijak dapat ditemukan di media sosial twitter. Tujuan penelitian ini adalah mendeskripsikan jenis ungkapan bijak di akun twitter @ kata2bijak. Pendekatan penelitian ini kualitatif dan jenis penelitiannya deskriptif. Data yang digunakan dalam penelitian ini merupakan ungkapan bijak di dalam akun twitter @kata2bijak. Sedangkan sumber data yang digunakan dalam penelitian ini yaitu akun twitter @kata2bijak. Teknik analisis data dalam penelitian yang digunakan metode agih dan padan referensial. Keabsahan data dalam penelitian menggunakan triangulasi teori. Hasil penelitian berupa unggahan ungkapan bijak di akun twitter @kata2bijak dengan nilai pendidikan karakter kreatif dan bersahabat/komunikatif menunjukkan karakter kreatif dapat membentuk kekuatan mental pada diri seseorang dan dapat membuat seseorang memiliki pengalaman baru, sedangkan karakter bersahabat/komunikatif dapat menjaga hubungan baik dengan orang lain dan diri sendiri.
\end{abstract}

Kata Kunci: Ungkapan Bijak; Twitter; Nilai Pendidikan Karakter

\begin{abstract}
Language that is categorized as unwise expressions can be found on twitter social media. The purpose of this study is to describe the types of wisdom expressions on the twitter account @ kata2bijak. This research approach is qualitative, and the type of research is descriptive. The data used in this study are expressions of wisdom in the @ kata2bijak twitter account. While the data source that will be used in this study is the twitter account @kata2bijak. The data analysis technique used in this research is the distributional method and referenrial (identity) method. The validity of the data in the study used theoretical triangulation. The results of the research in the form of uploading wise expressions on the Twitter account @ kata2bijakwith the value of creative and friendly/ communicative character education show that creative characters can form mental strength in a person and can make someone have new experiences, while friendly/communicative characters can maintain good relations with others. and himself.
\end{abstract}

Keywords: Word of Wisdom; Twitter; Value of Character Education

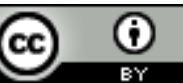

Creative Commons Attribution 4.0 International (CC BY 4.0) 


\section{PENDAHULUAN}

Setiap individu memiliki akses dengan sesama di era modern melalui media sosial Twitter. Pada unggahan media sosial Twitter setiap individu dapat saling menegur, membicarakan sesuatu, memberi saran, bahkan mengkritik. Selain itu bentuk bahasa yang dikategorikan sebagai ungkapan-ungkapan tidak bijak dapat ditemukan pula di media sosial Twitter. Emosi yang tidak terkendali menjadi faktor penyebab perilaku yang melanggar etika dan moral. Hal ini senada dengan Lickona, (2016: 20-29) bahwa terdapat 10 indikasi gejala penurunan moral yang perlu mendapatkan perhatian agar berubah ke arah yang lebih baik; 1) kekerasan dan tindakan anarki, 2) pencurian, 3) tindakan curang, 4) pengabaian terhadap aturan yang berlaku, 5) tawuran antar siswa, 6) ketidaktoleran, 7) penggunaan bahasa yang tidak baik, 8) kematangan seksual yang terlalu dini dan penyimpangannya, 9) sikap perusakan diri, 10) penyalahgunaan narkoba.

Ungkapan bijak termasuk jenis unggahan berbentuk tulisan dan lisan yang dapat ditemukan di media sosial Twitter. Melalui bahasanya ungkapan bijak dapat berpotensi sebagai media penanaman karakter. Ungkapan-ungkapan bijak mengandung nilai-nilai etika dan moral yang dapat memberikan efek positif kepada pengguna bahasa saat proses komunikasi berlangsung. Ungkapan bijak berisi rangkaian kata-kata yang mengandung pesan positif. Kata ungkapan dalam KBBI online bermakna apa-apa yang diungkapkan; kelompok kata atau gabungan kata yang menyatakan makna khusus (makna unsurunsurnya sering kali menjadi kabur); gerak mata (tangan dan sebagainya), perubahan air muka yang menyatakan perasaan hati. Kata bijak dalam KBBI online bermakna selalu menggunakan akal budinya. Dengan demikian dapat dikemukakan bahwa ungkapan bijak adalah kelompok kata atau gabungan kata yang menyatakan makna khusus yang dibuat menggunakan akal budi dan bersifat positif.

Penggunaan bahasa santun dalam penanaman karakter memiliki hubungan yang erat (Suminah, 2021: 3). Sebagaimana diketahui bahasa memiliki peran dan fungsi penting ketika proses penanaman karakter berlangsung (Fatmawati \& Sudiyana, 2021: 4). Penanaman nilai-nilai karakter harus ditumbuhkan dengan proses pembiasaan dalam keseharian (habituasi) melalui budaya sekolah (school culture) yang merupakan kunci dari keberhasilan pendidikan karakter (Nashihin, 2017: 22). Dengan asumsi bahwa ungkapan bijak yang berupa kutipan kata-kata motivasi dapat menggambarkan konstruksi dan representasi realitas kehidupan, kebudayaan dan nilai-nilai yang akan berdampak besar dalam meningkatkan kualitas pendidikan karakter.

Istilah karakter berpadanan dengan character dalam bahasa Inggris, dari kata bahasa Yunani charassein yang artinya 'membuat dalam', suatu tindakan untuk membantu setiap individu menjadi lebih semangat untuk membangun dirinya semaksimal mungkin dengan tujuan untuk menjadi insan yang memiliki perilaku berkarakter (Wahyunianto, 2019: 1). Karakter dapat digambarkan sebagai cara berpikir dan berprilaku yang menjadi ciri khas tiap individu untuk hidup dan bekerjasama, baik dalam lingkup keluarga, masyarakat, bangsa dan negara. Individu yang berkarakter baik adalah individu yang bisa membuat keputusan dan siap mempertanggungjawabkan tiap akibat dari keputusan yang dibuat sendiri.

Pada dasarnya sebagai mahluk sosial tentu menjalin hubungan dengan orang lain. Perilaku yang mencerminkan karakter baik ini mampu mengembangkan nilai pendidikan karakter bersahabat/komunikatif. Kerukunan sosial menggambarkan pola pikir yang kreatif dalam beradaptasi, berhubungan, dan bersikap kepada orang lain. Kreatif berarti menemukan banyak cara untuk selalu bersikap dan menjadi teladan yang baik (Watson, 2019: 208). Perilaku dan kebiasaan yang baik muncul sebagai bentuk sikap kreatif yang 
mampu mengembangkan nilai pendidikan karakter kreatif (Kieran, 2014: 128). Dengan menguatkan pemahaman spiritual dalam pikiran individu secara otomatis penanaman nilai pendidikan karakter kreatif dan bersahabat/komunikatif dapat dilakukan, karena sebuah kebaikan dan aturan-aturan hidup terdapat dalam ajaran agama. Selain itu kehidupan masa kecil seseorang berpengaruh dalam pembentukan karakter (Silalahi, Kuncara \& Wati, 2018: 262).

Indonesia sebagai negara yang merdeka, tentu memiliki dasar tersendiri dalam merumuskan nilai-nilai karakter. Rumusan nilai karakter yang dimaksud adalah sebagai berikut: 1) religius, 2) jujur, 3) toleransi, 4) disiplin, 5) kerja keras, 6) kreatif, 7) mandiri, 8) demokratis, 9) rasa ingin tahu, 10) semangat kebangsaan, 11) cinta tanah air, 12) menghargai prestasi, 13) bersahabat/komunikatif, 14) cinta damai, 15) gemar membaca, 16) peduli lingkungan, 17) peduli sosial, 18) tanggung jawab (Kemendiknas, 2010).

Nilai-nilai karakter tersebut, harus diajarkan secara sistematis dalam model pendidikan holistic yang menggunakan metode knowing the good, feeling the good, dan acting the good. Knowing the good bisa mudah diajarkan sebab pengetahuan bersifat kognitif saja. Setelah knowing the good harus ditumbuhkan feeling loving the good, yakni bagaimana merasakan dan mencintai kebaikan menjadi suatu alat yang bisa membuat orang senantiasa mau berbuat suatu kebaikan. Dengan cara demikian akan tumbuh kesadaran bahwa orang mau melakukan perilaku kebaikan, karena perilaku kebaikan itu membuat setiap orang senang. Setelah terbiasa melakukan kebaikan, maka acting the good itu berubah menjadi kebiasaan (Harahap, 2019: 7-8).

Tanto, Hapidin, \& Supena (2019) menemukan nilai-nilai karakter sabar, tekun, teliti, mandiri, tanggung jawab, disiplin, dan gotong royong pada anak usia dini dengan membuat karya-karya tatah sungging yang merupakan kesenian yang berkaitan dengan wayang kulit. Kemudian Ramdhani, Yuliastri, Sari, \& Hasriah (2019) menemukan nilainilai tanggung jawab, mandiri, jujur, religius, dan kerjasama pada anak Taman KanakKanak di TK Ummi Adniyah NW Sekarteja. Ramdhani, Yuliastri, Sari, \& Hasriah (2019), menjadikan kegiatan storytelling dengan menggunakan cerita rakyat sebagai pembudayaan nilai-nilai karakter. Selain itu Wati \& Nurdiana (2020) menemukan nilainilai karakter pula melalui permainan tradisional Aceh Tak-Tak Galah dan Taloo Yeye. Nilai-nilai karakter tersebut meliputi kejujuran, keberanian, kerjasama, patuh pada aturan dan tenggang rasa. Wati \& Nurdiana (2020) menjadikan tradisional Aceh Tak-Tak Galah dan Taloo Yeye sebagai pembudayaan nilai-nilai karakter.

Penelitian penanaman nilai pendidikan karakter pernah dilakukan pula oleh Gaspersz \& Uktolseja (2021) hasilnya nilai-nilai pendidikan karakter disiplin, kerja keras, mandiri, peduli lingkungan, tanggung jawab, toleransi, dan peduli sesama tercermin dalam cerita rakyat daerah Maybrat. Kemudian Dewi \& Handayani (2019) menemukan nilai-nilai karakter belajar bekerja sama, kekompakan, toleransi, kejujuran, kedisiplinan, kerja keras, meningkatkan kreativitas, mandiri, demokratis, rasa ingin tahu, semangat kebangsaan, menghargai, kepemimpinan, kerja sama, peduli lingkungan, peduli sosial, tanggung jawab, religius dan gemar membaca melalui permainan outdoor yang bersifat edukatif. Selanjutnya Sembiring \& Br Pakpahan (2021) menemukan enam nilai-nilai karakter dalam novel $5 \mathrm{~cm}$ karya Donny Dhirgantoro. Novel $5 \mathrm{~cm}$ mencerminkan nilai pendidikan karakter religius, kerja keras, gemar membaca, bersahabat/komunikatif, peduli sosial, dan cinta tanah air.

Nanda, Simbolon, Damanik, \& Semibiring (2021) menemukan pula nilai pendidikan karakter melalui cerita rakyat Timun Mas. Nilai pendidikan karakter tersebut meliputi, nilai religius, kemandirian, rasa ingin tahu, kerja keras, tanggung jawab, 
kejujuran, kreativitas, dan nilai semangat kerja keras. Kemudian (Zein, Saputra, \& Feriawan (2021), meneliti tentang nilai pendidikan karakter mandiri dalam Q.S. alInsyirah. Sub nilai mandiri tersebut berupa sikap selalu bersyukur, jangan putus asa, istikamah, dan tawakal. Selanjutnya (Suryanto, Andayani, \& Wardani (2021) menemukan nilai pendidikan karakter jujur, peduli, dan perhatian dalam novel Koplak karya Oka Rusmini.

\section{METODE PENELITIAN}

Pendekatan penelitian ini kualitatif dan jenis penelitiannya deskriptif yang bertujuan menguraikan suatu pokok secara sistematis (Kriyantoro, 2014: 67). Data yang digunakan dalam penelitian ini merupakan ungkapan bijak di dalam akun Twitter @kata2bijak, sedangkan sumber data yang digunakan dalam penelitian ini yaitu akun Twitter@kata2bijak. Teknik analisis data menggunakan metode agih dengan teknik sisip dan padan referensial. Teknik sisip dilakukan dengan menyisipkan unsur pembentuk satuan lingual untuk mengetahui keeratan hubungan antar unsur (Sudaryanto, 2015: 85). Metode padan referensial digunakan untuk mengetahui perbedaan oleh satuan lingual kata atau frasa yang melibatkan daya pilah yang bersifat mental (Sudaryanto, 2015: 27). Teknik validasi data dalam penelitian menggunakan triangulasi teori, yaitu dengan membandingkan teori tentang nilai pendidikan karakter kreatif dan bersahabat/komunikatif.

\section{HASIL DAN PEMBAHASAN}

\section{Hasil}

\section{Ungkapan Bijak Nilai Kreatif}

Kata kreatif berasal dari bahasa Inggris create yang memiliki arti menciptakan. Dalam konteks ini kreatif dapat berarti mengubah sikap menjadi lebih baik dengan melakukan hal-hal baik. Seseorang dapat mengembangkan sikap kreatif dalam dirinya melalui pelatihan, pengalaman, dan pengembangan intelektual Talebi \& Irannejad (2020:31).

1. (Seseorang) (harus) (men)jadikan kritikan sebagai batu loncatan (dan) menjadikan tatapan yang meremehkan sebagai motivasi.

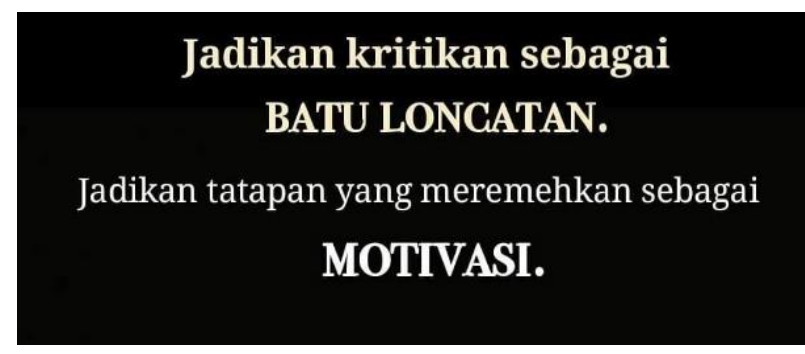

Gambar1 Ungkapan bijak di akun Twitter@kata2bijak

Ungkapan pada gambar 1 menunjukkan nilai karakter kreatif. Ditandai dengan klausa menjadikan kritikan sebagai batu loncatan. Ungkapan ini bermakna untuk memberi pelajaran kepada seseorang agar bersedia mendengarkan kritik dari orang lain dan mengubahnya menjadi dorongan untuk terus melangkah. Penerapan sikap kreatif mengikuti ungkapan di atas dapat membentuk kekuatan mental pada diri 
seseorang.

Seseorang yang termotivasi untuk berkreasi akan mulai percaya diri dalam bersikap dan bertindak (Piske, Stoltz, Rocha, \& Costa-Lobo, 2020: 218). Kemudian perubahan perilaku yang tepat dapat muncul pada diri seseorang melalui proses berpikir kreatif. Dengan pemikiran yang kreatif seseorang memiliki keberanian dalam mengambil tindakan dan mengatasi perasaan putus asa yang disebabkan oleh tindakan seseorang.

Dalam agama Islam mengajarkan pula penanaman karakter kreatif. Ayat-ayat Al-Quran telah menjelaskan bahwa setiap orang hendaknya bersikap baik kepada siapa saja. Seperti yang terdapat pada terjemahan Q.S. al-A'raf ayat 56, "Sesungguhnya rahmat Allah sangat dekat kepada orang yang berbuat kebaikan". Ayat ini menerangkan agar manusia semangat melakukan hal-hal yang baik. Ungkapan bijak (2) juga merujuk pada Q.S. al-A'raf ayat 56.

2. Akan ada cerita baru yang dimulai ketika cerita (telah) lama berakhir.

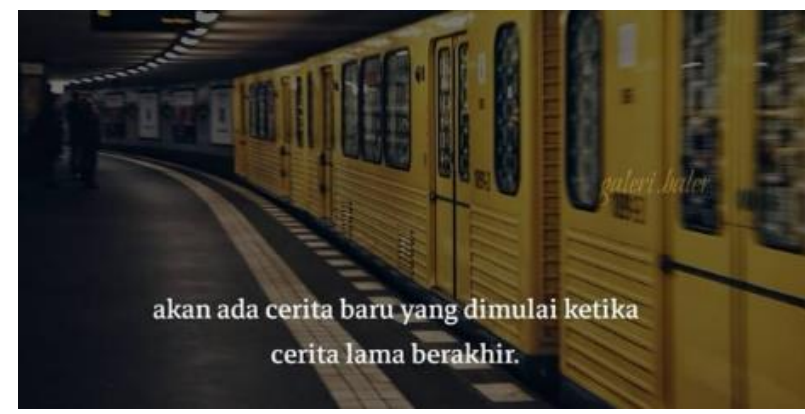

Gambar 2 Ungkapan bijak di akun Twitter @kata2bijak

Ungkapan pada gambar 2 menunjukkan nilai karakter kreatif. Ditandai dengan frasa cerita baru. Ungkapan ini bermakna untuk memberi pelajaran kepada seseorang agar melakukan atau mengikuti kegiatan yang bermanfaat. Penerapan sikap kreatif mengikuti ungkapan di atas dapat membuat seseorang memiliki pengalaman baru.

Kreativitas membuat seseorang mampu menemukan aspek-aspek baru, di sisi lain membuat seseorang mampu melewati pelajaran yang baru pula serta dapat membuat seseorang mengubahnya menjadi pengalaman yang baru, karena pengaruh dari pengetahuan yang dimiliki (Wolska-Długosz, 2015: 2906). Potensi kreatif seseorang dikembangkan melalui kegiatan-kegiatan sederhana yang memicu timbulnya ide-ide baru (Hardiyanti, 2020: 135).

3. Ungkapan Bijak Nilai Bersahabat/Komunikatif

Kata kreatif berasal dari bahasa Inggris create yang memiliki arti menciptakan. Dalam konteks ini bersahabat/ komunikatif berarti juga berlapang dada setelah mencoba melakukan yang terbaik. Seseorang yang memiliki karakter baik tentu akan mencoba melakukan yang terbaik terhadap Tuhan Yang Maha Esa, dirinya sendiri, orang lain, lingkungan, bangsa, negara, serta dunia internasional melalui pengembangan potensi yang disertai dengan pemahaman, emosi, dan juga motivasi (Zubaedi, 2011: 11).

4. Sehati bukan karena memberi, (te)tapi karena saling memahami. 


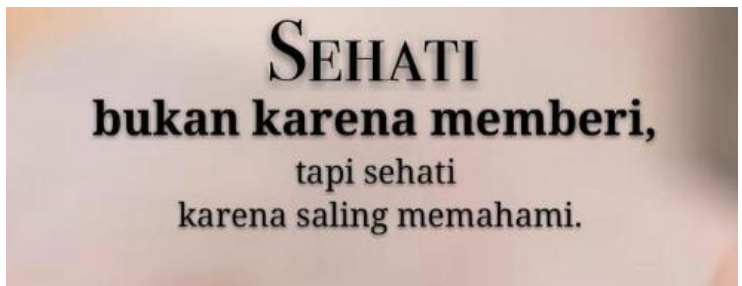

Gambar 3 Ungkapan bijak di akun Twitter@kata2bijak

Ungkapan pada gambar 3 menunjukkan nilai karakter bersahabat/komunikatif. Ditandai dengan klausa saling memahami. Ungkapan ini bermakna untuk memberi pelajaran kepada seseorang agar berusaha melakukan tindakan yang dapat menjaga hubungan baik dengan orang lain. Penerapan sikap bersahabat/komunikatif mengikuti ungkapan di atas dapat membuat seseorang memiliki kesempatan untuk saling bekerja sama melakukan yang terbaik.

Penanaman kemampuan bekerja sama bermaksud agar seseorang memiliki kemampuan untuk melakukan sosialisasi, melakukan interaksi, memiliki rasa toleransi, memahami satu sama lain untuk mencapai tujuan bersama (Prabandari \& Fidesrinur, 2021: 97). Dengan lebih memahami orang lain terlebih orang yang berbeda maka dapat dikatakan jika seseorang tersebut telah berhasil dalam mengelola dalam sebuah tim (Wiguna, 2017: 233).

Agama Islam mengajarkan pula penanaman karakter bersahabat/komunikatif. Ayat-ayat Al-Quran telah menjelaskan bahwa setiap orang harus berlapang dada agar dimudahkan dalam setiap urusan. Seperti yang terdapat pada terjemahan Q.S. Thaha ayat 25-26, "Dia (Musa) berkata: "Ya Tuhanku, lapangkanlah dadaku, dan mudahkanlah urusanku,". Ayat ini menerangkan agar manusia mampu meneguhkan hatinya dengan lapang dada. UB Ungkapan bijak (4) dan (5) juga merujuk pada Q.S. Thaha ayat 153.

5. Baik adalah pilihan meski jalan yang ditempuh tidak baik baik saja.

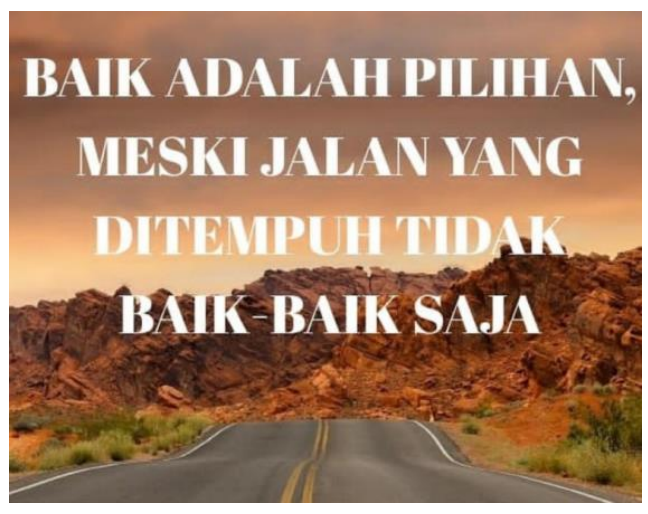

Gambar 4 Ungkapan bijak di akun Twitter@kata2bijak

Ungkapan pada gambar 4 menunjukkan nilai karakter bersahabat/komunikatif. Ditandai dengan klausa baik adalah pilihan. Ungkapan ini bermakna untuk memberi pelajaran kepada seseorang agar berusaha melakukan tindakan yang dapat menjaga hubungan dengan diri sendiri. Penerapan sikap bersahabat/komunikatif mengikuti ungkapan di atas dapat membuat seseorang 
memiliki kesiapan untuk menghadapi masa sulit.

Tindakan-tindakan kecil dalam keadaan tidak baik dapat mendominasi pengambilan keputusan seseorang (Carlson, 2020: 21). Pengambilan keputusan yang benar dan dengan melibatkan orang lain akan mampu menyelesaikan beragam permasalahan dengan tepat (Mustakim, 2020: 191). Seseorang memiliki rasa optimis dalam mengambil keputusan di setiap keadaan dengan percaya diri.

6. Perihal masa lalu biarkan semua rasa terkenang meski ia masih tergenang bersama waktu yang telah berlalu.

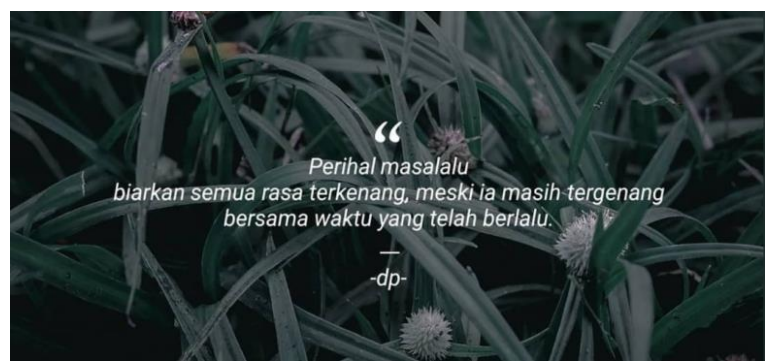

Gambar 5 Ungkapan bijak di akun Twitter@kata2bijak

Ungkapan pada gambar 5 menunjukkan nilai karakter bersahabat/komunikatif. Ditandai dengan klausa biarkan semua rasa terkenang. Ungkapan ini bermakna untuk memberi pelajaran kepada seseorang agar berusaha melakukan tindakan yang dapat menjaga hubungan baik dengan diri sendiri. Penerapan sikap bersahabat/komunikatif mengikuti ungkapan di atas dapat membuat seseorang memiliki kesiapan untuk menerima kenyataan yang ada dan menjalani hidup.

Sudut pandang dalam melihat permasalahan mempengaruhi pemikiran seseorang. Seseorang yang merasa sebagai korban atas permasalahan yang terjadi memiliki kondisi emosional yang tidak baik, seperti, tidak mengambil tanggung jawab, mengalami stagnasi dalam hidup, memegang dendam, sulit bersikap tegas, merasa tidak berdaya, tidak percaya pada orang lain, tidak tahu kapan mengatakan cukup, mudah terprovokasi dan selalu berdebat masalah sepele, mengasihani diri sendiri, terus membandingkan diri dengan orang lain, dan merendahkan orang lain (Indra, 2019: 8-15). Hal ini tentu harus dihindari agar seseorang dapat menjalani hidup dengan damai.

\section{Pembahasan}

Ungkapan bijak dalam akun Twitter @kata2bijak mencerminkan nilai-nilai karakter kreatif dan peduli sosial sehingga peneliti hanya berfokus pada nilai-nilai yang telah ditemukan dalam ungkapan bijak dari unggahan akun Twitter @kata2bijak. Penelitian yang dilakukan oleh Purnomo \& Wahyudi, (2020) berkaitan pula dengan ungkapan kebijaksanaan. Purnomo \& Wahyudi (2020) menemukan subnilai religius yaitu cinta damai, percaya diri, toleransi, persahabatan, dan mencintai lingkungan dalam ungkapan hikmah di sekolah dasar se-Karesidenan Surakarta.

Nilai-nilai karakter yang ditemukan oleh Wardani, , Al-Ma'ruf, \& Prayitno (2020) dalam wacana berita yakni sepuluh nilai yaitu nilai religius, profesionalisme, kejujuran, sumber nilai, kreatif, cinta damai, semangat juang, cinta lingkungan, cinta tanah air, dan kerukunan. Sejalan dengan itu penelitian yang dilakukan oleh Aziz, Putra, \& Rusda 
(2021), berkaitan pula dengan nilai- nilai karakter. Aziz, Putra, \& Rusda (2021) menemukan nilai karakter jujur, berani, disiplin, sopan, pekerja keras, dan gemar membaca dalam ragam peribahasa atau yang biasa disebut pepatah-petitih bahasa Dayak. Kemudian penelitian yang dilakukan oleh Handayani, Megawati, \& Malia (2016) Handayani, juga menemukan nilai karakter religius, toleransi, disiplin, kerja keras, demokratis, rasa ingin tahu, menghargai prestasi, bersahabat/komunikatif, dan peduli sosial dalam buku Wirbesucheneine Moschee (WBM) 'Kami Mengunjungi Masjid'.

\section{SIMPULAN}

Pada unggahan ungkapan bijak di akun Twitter@kata2bijak nilai pendidikan karakter kreatif dan bersahabat/komunikatif dapat ditanamkan. Nilai pendidikan karakter kreatif dapat membentuk kekuatan mental pada diri seseorang dan dapat membuat seseorang memiliki pengalaman baru. Nilai pendidikan karakter bersahabat/komunikatif dapat menjaga hubungan baik dengan orang lain dan diri sendiri. Pengembangan karakter yang baik dapat dilakukan melalui pelatihan, pengalaman, dan pengembangan intelektual. Mencoba melakukan yang terbaik kepada siapa pun termasuk diri sendiri sebagai cerminan nilai pendidikan karakter bersahabat/komunikatif menggambarkan pola pikir yang kreatif dalam berhubungan dan bersikap kepada orang lain. Perilaku yang tepat dapat muncul pada diri seseorang melalui proses berpikir kreatif. Sikap percaya diri mampu memotivasi seseorang melakukan tindakan yang tepat. Seseorang yang melakukan tindakan yang tepat mencerminkan nilai pendidikan karakter kreatif.

\section{DAFTAR PUSTAKA}

Aziz, A., Putra, D., \& Rusda, D. (2021). Pengembangan model pendidikan karakter berbahasa dayak ngaju di sekolah dasar Kota Sampit. Jurnal Studi Guru Dan Pembelajaran, 4(1), 95-104. https://e-journal.my.id/jsgp/article/view/526

Carlson, R. (2020). Mengatasi masalah besar dalam hidup: Menemukan kekuatan dan bergerak maju walau rintangannya berat. PT Gramedia Pustaka Utama.

Dewi, T. U., \& Handayani, S. L. (2019). Penanaman nilai karakter melalui permainan outdoor bagi anak-anak usia dini di wilayah RW 01 Kelurahan Pekayon Kecamatan Pasar Rebo Jakarta Timur. Publikasi Pendidikan, 9(1), 1-6. https://doi.org/10.26858/publikan.v9i1.6418

Fatmawati, M., \& Sudiyana, B. (2021). Nilai-nilai karakter pada buku siswa sekolah dasar tema keluargaku. Scaffolding: Jurnal Pendidikan Islam Dan Multikulturalisme, $3(1)$, $1-15$. https://ejournal.insuriponorogo.ac.id/index.php/scaffolding/article/view/630

Gaspersz, S., \& Uktolseja, L. J. (2021). The pedagogical implication of maybrat oral literature (elements and value of character education). Interaction: Jurnal Pendidikan Bahasa, 8(1), 62-72. https://unimuda.ejournal.id/jurnalinteraction/article/view/911

Handayani, T. K. (2016). Nilai-nilai karakter dalam tindak tutur ilokusi dalam buku Wir Besuchen Eine Moschee. Litera, 15(2), 305-318. https://doi.org/10.21831/1tr.v15i2.11831

Harahap, A. C. P. (2019). Character building pendidikan karakter. Al-Irsyad, 9(1), 1-11. http://jurnal.uinsu.ac.id/index.php/al-irsyad/article/view/6732

Hardiyanti, W. D. (2020). Aplikasi bermain berdasarkan kegiatan seni lukis untuk stimulasi kreativitas anak usia 5-6 tahun. Jurnal Pendidikan Anak, 9(2), 134-139. https://journal.uny.ac.id/index.php/jpa/article/view/31664 
Indra, D. (2019). Berdamai dengan kenyataan hidup: Bangkit dari kegagalan dan raih kesusksesan. Anak Hebat Indonesia.

KBBI. (2016). Kamus besar bahasa Indonesia. https://kbbi.kemdikbud.go.id/

Kemendiknas. (2010). Bahan pelatihan penguatan metodologi pembelajaran berdasarkan nilai-nilai budaya untuk membentuk daya saing dan karakter bangsa. Kementerian Pendidikan Nasional, Badan Penelitian dan Pengembangan, Pusat Kurikulum.

Kieran, M. (2014). Creativity as a virtue of character. The Philosophy of Creativity: New Essays, 125-144. https://doi.org/10.1093/acprof:oso/9780199836963.003.0007

Kriyantoro, R. (2014). Teknik praktis riset komunikasi. Kencana.

Lickona, T. (2016). Mendidik untuk membentuk karakter: Bagaimana sekolah dapat memberikan pendidikan tentang sikap hormat dan bertanggung jawab. PT. Bumi Aksara.

Mustakim, B. (2020). Perspektif psikologi pengambilan keputusan dalam kepemimpinan pendidikan. Irsyad: Jurnal Bimbingan, Penyuluhan, Konseling, Dan Psikoterapi Islam, 8(2), 183-198. https://doi.org/10.15575/IRSYAD.V8I2.1965

Nanda, D. D., Simbolon, B., Damanik, F. A., \& Sembiring, Y. B. (2021). Moral value and character building education in folklore from Central Java "Timun Mas." Journal of Languages and Language Teaching, 9(1), 85-91. https://ejournal.undikma.ac.id/index.php/jollt/article/view/3319

Nashihin, H. (2017). Pendidikan karakter berbasis budaya pesantren. Semarang: Formaci.

Piske, E. F. H. R., Stoltz, T., Rocha, A., \& Costa-Lobo, C. C. (2020). Motivated or unmotivated for the creative approach: Values from a highly able learner's point of view.

Prabandari, I. R., \& Fidesrinur, F. (2021). Meningkatkan kemampuan bekerjasama anak usia 5-6 tahun melalui metode bermain kooperatif. Jurnal Anak Usia Dini Holistik Integratif (AUDHI), 1(2), 96-105. https://doi.org/10.36722/jaudhi.v1i2.572

Purnomo, E., \& Wahyudi, A. B. (2020). Nilai pendidikan karakter dalam ungkapan hikmah di SD se-Karesidenan Surakarta dan pemanfaatannya di masa pandemi. Qalamuna: Jurnal Pendidikan, Sosial, Dan Agama, 12(2), 183-193. https://doi.org/10.37680/qalamuna.v12i2.561

Ramdhani, S., Yuliastri, N. A., Sari, S. D., \& Hasriah, S. (2019). penanaman nilai-nilai karakter melalui kegiatan storytelling dengan menggunakan cerita rakyat sasak pada anak usia dini. Jurnal Obsesi: Jurnal Pendidikan Anak Usia Dini, 3(1), 153169. https://journal.ikipsiliwangi.ac.id/index.php/project/article/view/7073/pdf

Sembiring, R. L. N., \& Br pakpahan, E. M. (2021). Analysis of education value of character in novel $5 \mathrm{~cm}$ by Donny Dhirgantoro. Project (Professional Journal of English Education), 4(3), 535-541. https://journal.ikipsiliwangi.ac.id/index.php/project/article/view/7073/pdf

Silalahi, S. R. A., Kuncara, S. D., \& Wati, E. (2018). An analysist of moral development of Nim Rouse character in Nim's Island Film. Jurnal Ilmu Budaya, 2(3), 261267. http://e-journals.unmul.ac.id/index.php/JBSSB/article/view/1153/pdf

Sudaryanto. (2015). Metode dan teknik analisis bahasa. Sanata Dharma University Press.

Suminah, S. (2021). Penerapan bahasa santun terhadap pendidikan karakter anak usia dini di Paud Buah Hati Kabupaten Aceh Tengah. Jendela Anak, 1(1), 1-26. https://journal.stkipm-bogor.ac.id/index.php/jendelaanak/article/view/65

Suryanto, S., Andayani, A., \& Wardhani, N. E. (2021). Reflection of character education 
value through depictions of characters in Oka Rusmini's Koplak Novel. International Journal of Multicultural and Multireligious Understanding, 8(2), 78-86. http://dx.doi.org/10.18415/ijmmu.v8i2.2318

Talebi, S., \& Irannejad, P. (2020). Comparing the descriptive assessment in terms of critical and creative thinking among the sixth grade students in the public and private schools. Journal of Social Sciences and Humanities Research, 8(1), 2937. https://journals.researchub.org/index.php/JSSHR/article/view/927

Tanto, O. D., Hapidin, H., \& Supena, A. (2019). Penanaman karakter anak usia dini dalam kesenian tradisional Tatah Sungging. Jurnal Obsesi: Jurnal Pendidikan Anak Usia Dini, 3(2), 337-345. https://doi.org/10.31004/obsesi.v3i2.192

Wahyunianto, S. (2019). Implematasi pembiasaan diri dan pendidikan karakter: Sebagai pengantar. Deepublish.

Wardani, L. S. P., Al-Ma'ruf, A. I., \& Prayitno, H. J. (2020). Nilai karakter dalam ungkapan hikmah bersumberkan wacana berita. Jurnal Analisa Sosiologi, 9, 329342. https://doi.org/10.20961/jas.v9i0.43177

Wati, E., \& Nurdiana. (2020). Penanaman nilai karakter remaja melalui permainan tradisional. Jurnal Sains Riset, 9(3), 52-60. http://journal.unigha.ac.id/index.php/JSR/article/view/159

Watson, L. (2019). Educating for inquisitiveness: A case against exemplarism for intellectual character education. Journal of Moral Education, 48(3), 303-315. https://doi.org/10.1080/03057240.2019.1589436

Wiguna, I. B. (2017). Teori dan aplikasi latihan kondisi fisik. Rajawali Pers.

Wolska-Długosz, M. (2015). Stimulating the development of creativity and passion in children and teenagers in family and school environment - Inhibitors and Opportunities to Overcome them. Procedia-Social and Behavioral Sciences, 174, 2905-2911. https://doi.org/10.1016/j.sbspro.2015.01.1027

Zein, A., Saputra, E., \& Feriawan, F. U. (2021). The value of independent character education in surah Al-Insyirah. At-Tarbiyat: Jurnal Pendidikan Islam, 4(1), 4652. http://jurnal.staiannawawi.com/index.php/At-Tarbiyat/article/view/248

Zubaedi. (2011). Desain pendidikan karakter: Konsepsi dan aplikasinya dalam lembaga pendidikan. Kencana Prenada Media Group 